\title{
Extraction, Separation and Identification of Chemical Ingredients of Elephantopus Scaber L. Using Factorial Design of Experiment
}

\author{
Anees Ahmad \\ Environmental Technology Division \\ School of Industrial Technology \\ Univesriti Sains Malaysia \\ 11800 Penang, Malaysia \\ E-mail: anees@usm.my, aneesahmad@yahoo.com
}

Abbas F. M. Alkarkhi

Environmental Technology Division

School of Industrial Technology

Univesriti Sains Malaysia

11800 Penang, Malaysia

E-mail: abbas@usm.my

Sufia Hena

Environmental Technology Division

School of Industrial Technology

Univesriti Sains Malaysia

11800 Penang, Malaysia

E-mail: sufiahena@yahoo.co.in

Lim Han Khim

Environmental Technology Division

School of Industrial Technology

Univesriti Sains Malaysia

11800 Penang, Malaysia

E-mail: Hankhimzip@yahoo.com

\begin{abstract}
Soxhlet extraction technique is employed for the extraction and separation of chemical constituents in the medicinal plant, Elephantopus scaber L. The effect of parameters, such as different parts of the plant (leaves, roots and stems), extraction time and types of solvent (n-hexane and methanol) on the extracted yield and the percentage of extraction were investigated. The design of experiment was done using factorial design. The data were analyzed using ANOVA as well as factorial design. The experimental results show that the methanol is better than $n$-hexane but an extraction time of 9 hours was required for stems and roots while 12 hours for leaves. Essential crude of Elephantopus scaber $L$. obtained by Soxhlet extraction was further analyzed by gas chromatography-mass spectrometry detection to identify the chemical ingredients of the plant and used as a standard in the qualitative analysis for certain chemical compounds based on the retention time on the chromatogram. Six compounds such as stigmasterol, lupeol, stearic acid, deoxyelephantopin isomers, analogue 1 and analogue 2 of deoxyelephantopin have been identified. Oven temperature
\end{abstract}


program of gas chromatography has been developed in this research. The results obtained, enable one to make qualitative and quantitative analysis for the essential oil which was extracted from the herbal plant. Maximum extraction conditions of the stigmasterol and lupeol were determined by comparing the area percentage below the peak in chromatogram with the GCMS standard. Stigmasterol: 6 hours extraction time using n-hexane and stems show the highest area percentage (8.145\%). Lupeol: 9 hours extraction time using n-hexane and stems show the highest area percentage $(68.580 \%)$.

Key words: Soxhlet extraction technique, Elephantopus scaber L, Separation, GC, GC-MS

\section{Introduction}

The development of organic chemistry took place along with the study of plants, mainly in the 19th century, when the first studies on plants were scientifically recorded. This ended up in the isolation of some active compounds from plants (Wheelwring, E.G, 1974). It is the vegetal kingdom that has contributed, in a more meaningful way, to the supply of useful substances for the treatment of human diseases (Galhiane, M.S., 2006). Elephantopus scaber L. is a member of Asteraceae family. The whole plant of Elephantopus scaber $L$. is a perennial herb and is well known as a Chinese folk medicine which is widely used in the treatment of nephritis, edema, dampness, pain in the chest, fever and cough of pneumonia, scabies, and arthralgia due to wounding (Peer, L. M., 1980 \& Tsai, C. C, 1999). It is also commonly used as a remedy for the treatment of gastropathy, hepatitis, nephritis, edema, chest pain, fever and cough of pneumonia, bronchitis, arthritis, and carbuncle in China.

Elephantopus scaber L. is known to contain a large number of bioactive compounds such as lipids, phytochemicals, pharmaceutics and pigments. For example, ethyl hexadecanoate, ethyl-9, 12-octadecadienoate, ethyl-(Z)-9-octadecenoate, ethyl octadecanoate, lupeol, stigmasterol, stigmasterol glucoside, deoxyelephantopin (1) and two new germacranolide sesquiterpene lactones named 17, 19-dihydrodeoxyelephantopin (2) and iso-17, 19-dihydrodeoxyelephantopin.

In this study, extraction of Elephantopus scaber L. with Soxhlet extraction process has been studied experimentally. The advantages of applying conventional Soxhlet extraction include (a) the displacement of transfer equilibrium by repeatedly bringing fresh solvent into contact with the solid matrix (b) maintaining a relatively high extraction temperature and (c) no filtration requirement after leaching. Furthermore, the soxhlet extraction method requires simple and inexpensive equipment which is easy to operate. (Luque de Castro, 1998).

In this study, the soxhlet extraction of Elephantopus scaber L. is presented using methanol and n-hexane as extracting solvents because these might extract different compositions (Zarnowski, R., 2004). The most widely-used solvent to extract edible oils from plant sources is hexane which has a fairly narrow boiling point range of approximately $63-69^{\circ} \mathrm{C}$ and is excellent oil solvent in terms of oil solubility and ease of recovery (Mamidipally,P.K., 2004). Various extraction conditions including the solvent (n-hexane and methanol), time of extraction ( 3 hours, 6 hours, 9 hours and 12 hours), different parts of plant (leaves, stems, and roots), have been investigated.

On the issue of problem statements, the points which should be highlighted are:

(a) The studies on development of chromatographic method of Elephantopus scaber L. rarely found in literature and particularly none in Gas Chromatography (GC) method. As a result, the development of GC method such as oven temperature, carrier gas flow rate and detention time are quite challenging.

(b) Extracted essential oil of Elephantopus scaber L. may contain volatile chemical compounds and it is very difficult to trap them while transferring the essential oil into the sample storage bottle after extraction process. Therefore, the essential oil is to be cooled to room temperature before transferring process so that the volatile components will not evaporate easily since it will condense back when temperature is lower than its boiling point. Moreover, some chemical constituents of Elephantopus scaber L.were identified using Gas Chromatography - Mass Spectrometry (GCMS) during this research study.

\section{Material and methods}

\subsection{Sampling}

Fresh Elephantopus scaber L. with commercial maturity (the plant height approximately $50 \mathrm{~cm}$ with corolla $8 \sim 10 \mathrm{~mm}$ long purple flower) were obtained from a local garden. In order to ensure the sample used was from the same source throughout the experiment, the fresh sample was collected in sufficient quantities $(\sim 10 \mathrm{~kg})$ at a time. The standard procedure was followed to collect and store the sample.

The plant of Elephantopus scaber L. is separated into leaves, stem and root. First, the plant was washed thoroughly with running tap water, followed by rinsing with distilled water and then each part was cut into small pieces. The leaves, 
stems and roots were sun dried $\left(\sim 33^{\circ} \mathrm{C}\right)$ at open area with active ventilation until they attained constant weight (around two weeks).

\subsection{Particle size}

The sun dried parts of the plant were powdered in German Retsch mill, and then sieved into different mesh sizes $(>150,150,180,250$ and $300 \mu \mathrm{m})$ using Vibrator Sieve Shaker (Retsch, German) but only samples of selected particle size were used in this study. Each of the sample size after the sieving process was weighed to calculate the percentage particle size of the material present in the sample. All the samples were stored in air tight container respectively and kept in the refrigerator at temperature below $4{ }^{\circ} \mathrm{C}$ to maintain the freshness of sample and preserving the loss of volatile compounds present in the samples.

\subsection{Moisture content}

$5 \mathrm{gm}$ of each dried ground leaves, roots and stems respectively was dried in the oven (Model Memert) at $104{ }^{\circ} \mathrm{C}$ until constant weight. The initial weight and final weight were taken, the weight difference for each samples represents its moisture content. The moisture content determination process was repeated for three times. The $\%$ of moisture content is reported in this study.

\subsection{Soxhlet extraction}

The samples of dried leaves, roots and stems were removed from the refrigerator and kept at room temperature $\left(\approx 28^{\circ} \mathrm{C}\right)$ for 30 minutes to gently release the water vapor from the samples. This was done to retain the quality and amount of oil content in its original condition. The chosen particles sizes selected for the extraction are: leaves $<150 \mu \mathrm{m}$; roots $<150$ $\mu \mathrm{m}$ and stems $180 \mu \mathrm{m}$.

The weight of a blank thimble filter $(22 \times 90 \mathrm{~mm})$ (Advantec, Japan) and a blank round bottom extraction flask were weighed before and after placing 3 grams of sample into thimble. The cotton is then placed into the thimble and its weight along with sample was recorded again. The purpose of using cotton was to ensure the presence of samples inside the thimble during the experiment. The Soxhlet extraction processes using n-hexane ( $99 \%$ assay) and methanol (99.8\% assay) as extraction solvents were carried out to compare the percentage of extraction and their quality of extraction between the two solvents. $350 \mathrm{~mL}$ of solvent is poured into the round bottom extraction flask, weighed and placed on the heating mantle. After this, the thimble containing the sample was placed into the extraction chamber. Lastly, the condenser was placed on top of the extraction flask and all these parts were fixed vertically. The extraction was carried out for four different preset intervals of times, which is 3 hours, 6 hours, 9 hours and 12 hours respectively. The process was repeated three times and an average extraction was taken.

After the extraction process, the weight of thimble containing sample and the weight of round bottom extraction flask containing solvent and extracted crude were weighed. The extracted samples were calculated as percentage of extraction while the extracted oil was stored in a refrigerator at the temperature below $4{ }^{\circ} \mathrm{C}$ until analyzed by GC and GCMS after the soxhlet extraction process. The percentage of extraction was calculated by using the equation (1).

$$
\% \text { Extraction }=\frac{m_{1}-m_{2}}{m_{1}} \times 100
$$

Where:

$m_{1}=$ mass in grams of thimble and the sample before extraction

$m_{2}=$ mass in grams of thimble and the sample after extraction

\subsection{Analytical methods}

\subsubsection{Gas chromatography (GC)}

The extracted crude with solvent was analyzed by Shimadzu GC-17A Gas Chromatography (GC) system equipped with a flame ionization detector (FID). BP-X5 capillary column $(30 \mathrm{~m} \times 0.25 \mathrm{~mm}$ id), $0.25 \mu \mathrm{m}$ film thickness (SGE, Australia) was used. The helium carrier gas flow rate was $25 \mathrm{~mL} / \mathrm{min}$ at $600 \mathrm{kPa}$. The injector and detector temperature were maintained at $250{ }^{\circ} \mathrm{C}$ Injection was performed in split less mode and the volume was $1 \mu \mathrm{L}$. An oven temperature program with total run time of $51.6667 \mathrm{~min}$ was used. The column temperature, after an initial isothermal period of 2 min at $60{ }^{\circ} \mathrm{C}$ was increased to $200{ }^{\circ} \mathrm{C}$ at a rate of $5{ }^{\circ} \mathrm{C} / \mathrm{min}$, and maintained at this temperature for $2 \mathrm{~min}$, followed by the temperature was increased to $220^{\circ} \mathrm{C}$ at a rate of $3{ }^{\circ} \mathrm{C} / \mathrm{min}$, maintained at this temperature for $1 \mathrm{~min}$, and finally increased to $250{ }^{\circ} \mathrm{C}$ at a rate of $6{ }^{\circ} \mathrm{C} / \mathrm{min}$, and maintained at this temperature for $7 \mathrm{~min}$. A sample of $2 \mathrm{~mL}$ of extracted oil with solvent was drawn out by using a $5 \mathrm{~mL}$ syringe and placed into a $2 \mathrm{~mL}$ vial prior for gas chromatography analysis. The extraction was repeated three times for each extraction by using hexane and methanol respectively. 
Crude samples with solvent $(1 \mu \mathrm{L})$ were injected manually and peaks areas were calculated. The compounds in the GC were further identified by comparing its retention time with the results of GC-MS which was used as a standard.

\subsubsection{Gas chromatography - mass spectrometry (GC-MS)}

$5 \mathrm{~mL}$ of plant extract was evaporated to dryness and reconstituted in $200 \mu \mathrm{L}$ n-hexane or $200 \mu \mathrm{L}$ methanol. The extracts were then subjected to GC-MS analysis. Chromatographic separation was carried out with Hewlett Packard 6890 series Gas Chromatograph with Autosampler and 5973N Mass Selective Detector and Chemstation Data System and a HP-5 crosslinked $5 \%$ phenyl methyl siloxane fused silica capillary column, $30 \mathrm{~m} \times 0.25 \mathrm{~mm}$ (id), $0.25 \mu \mathrm{m}$ film thickness was used. Helium was used as a carrier gas with a flow rate of $0.9 \mathrm{~mL} / \mathrm{min}$. The GC-MS oven temperature was programmed as follows:

i. $\quad 50^{\circ} \mathrm{C}$ (hold 2.5 minutes) to $150^{\circ} \mathrm{C}$ at the rate of $15^{\circ} \mathrm{C} / \mathrm{min}$

ii. increased to $200{ }^{\circ} \mathrm{Cat}$ a rate of $3{ }^{\circ} \mathrm{C} / \mathrm{min}$

iii. increased to $300^{\circ} \mathrm{C}$ at a rate of $8{ }^{\circ} \mathrm{C} / \mathrm{min}$

iv. kept for another 8 minutes at $300^{\circ} \mathrm{C}$

Injection temperature was maintained at $250{ }^{\circ} \mathrm{C}$, interface temperature at $280{ }^{\circ} \mathrm{C}$, quadruple temperature at $150{ }^{\circ} \mathrm{C}$ and ion source temperature at $230^{\circ} \mathrm{C}$. Injection was performed in split less mode and the volume was $1 \mu \mathrm{L}$. The mass spectra of compounds in samples were obtained by electron ionization (EI) at $70 \mathrm{eV}$, and the detector operated in scan mode from 20 to $600 \mathrm{amu}$. Identifications were based on mass spectral matching with standard compounds in NIST and Wiley libraries $(\geq 90 \%)$ while identification of Deoxyelephantopin isomers and analogs were based on the molecular structure, molecular mass and calculated fragmentations.

The essential chemical constituents were identified by matching mass spectra with spectra of reference compounds in mass spectral library of National Institute of Standards and Technology (NIST 147). The relative amounts of individual components were expressed as percent peak areas relative to total peak area.

\subsection{Statistical analysis}

Statistical techniques such as analysis of variance (ANOVA) and factorial design were used for analyzing the data obtained from extraction experiment. The effect of three factors on percentage of extraction as a response variable, the factors are extraction time (four levels; 3, 6, 9, $12 \mathrm{hr}$ ), type of solvent (two types; $\mathrm{n}$-hexane and Methanol), and part of plant (three parts; leave, Root, Stem). Factorial design of type $4 \times 2 \times 3$ was used to carry out this experiment in random order (Montgomery, 2005). Three replicates were used for each combination and the total number of runs was 72 .

\section{Result and discussions}

\subsection{Particle size selection}

Five particle sizes of samples (leaves, roots and stems) were obtained as shown in Table 2.They are, smaller than 150 $\mu \mathrm{m}, 150 \mu \mathrm{m}, 180 \mu \mathrm{m}, 250 \mu \mathrm{m}$, and $300 \mu \mathrm{m}$. Leaves and roots with smaller than $150 \mu \mathrm{m}$ particle size were selected for further study due to its abundance compared to other sizes that is about $50.6 \%$ (leaves) and $93.9 \%$ (roots) of the total samples. Moreover, larger particles may result in prolonged extraction time because the extraction process may be diffusion-controlled where the oil has to diffuse out from the inner part of the particle to the surface through the matrix of the particle before the solubility process occurred. Besides that, the smaller the particle size the higher would be the extraction yield due to higher surface area to volume ratio and the specific surface area that was exposed to the solvent was increased. Therefore, the extraction yield increased with decreasing particle size.

According to Reverchon (Reverchon, E., 1997), if external mass transfer or equilibrium was the controlling step of the extraction process, the particle size could not affect the extraction rate significantly. On the other hand, if the internal mass transfer or diffusion was the controlling step of the extraction process, the particle size could significantly influence the extraction time. As a result, effect of solvents on the extraction time was the main consideration in this experiment and hence the particle size of each sample was fixed. However, stems samples with particles size $180 \mu \mathrm{m}$ was chosen due to the small amount of the smallest particle size (smaller than $150 \mu \mathrm{m}$ ) could be obtained in the total samples of stems.

\subsection{Moisture content on the extraction process}

In this study, the sun dried ground samples with particle size of $\leq 150 \mu \mathrm{m}$ (leaves and roots) and $180 \mu \mathrm{m}$ (stems) were used rather than the wet basis sample. Moreover, the wet sample will cause mechanical operational failure to the analytical instruments such as GCMS.

The moisture content of Elephantopus scaber $L$. leaves with particle size of $\leq 150 \mu \mathrm{m}$ was found to be $8.94 \%$, roots with particle size of $\leq 150 \mu \mathrm{m}$ was found to be $8.72 \%$ and stems with particle size $180 \mu \mathrm{m}$ was found to be $8.60 \%$ as shown in 
Table 3. High moisture content could induce 'unwanted phenomenon' which will result in lesser yield and lower quality of extract.

The moisture content of leaves is the highest (8.94\%), followed by roots $(8.72 \%)$ and stems $(8.60 \%)$. This can be explained that the leaf hairs of the plant minimize the water loss from its stomata. The high storage level of water moisture in the leaf is for the photosynthesis purposes. The moisture content of roots is higher than stem because stem only acts as a passage for water transport in a plant while roots are the sources where water enters and contains a high level of moisture content.

\subsection{Percentage of extraction}

The influences of nature of solvents and total time of extraction on the percentage extraction yield are shown in Table 4, 5 and 6 . The different yields of extracts with methanol and n-hexane might be influenced by the polarities of solvents (Luque de Castro, 1994 \& Romdhane, M., 2002).

Table 4 shows that the percentage extraction yield for leaves with methanol was better than $\mathrm{n}$-hexane. The average extracted yield by methanol is almost $50 \%$ more than average extracted yields by $n$-hexane. For example, the average yield from leaves in methanol at 12 hours was $14.08 \%$ while in $n$-hexane it was $7.45 \%$ and thus, the difference was about $89 \%$ higher in methanol. This was also reported by Klejdus et al. (Klejdus,B., 2004 \& Klejdus, B., 2005) that methanol is a better solvent during their research on comparing the different extraction conditions including solvents and techniques for extraction of isoflavones soybeans samples.

For root of Elepantopus scaber L, methanol was reported better than n-hexane solvent regarding the yield of extraction in percentage. According to Zlotorzynski, A (Zlotorzynski, A., 1995), methanol has relatively higher dissipation factor, which means that it could absorb much of the microwave energy and transform it into heat better than other solvents. Hence, the most favourable extraction time for methanol in roots' extraction was reported as 9 hours (10.17\%) and 6 hours for n-hexane (6.07\%) which was related to the extracted yield in percentage of extraction, as reported in Table 5.

Table 6 shows the extraction yield of stem of Elephantopus scaber L. which indicate that methanol was better than $\mathrm{n}$-hexane as solvent. The highest percentage of the extraction of stems among four different length of time such as $5.26 \%$ of extraction for 9 hours (n-hexane) and $10.18 \%$ of extraction for 9 hours (methanol). The best duration of extraction of stem using n-hexane was 9 hours. It was different with other parts of the plant where 6 hours the best extraction period was.

\subsection{Qualitative and Quantitative Analysis}

The quantitative determination of the chemical compounds was based on the comparison of peak areas of samples with those in GCMS library. Some of the identified compounds are stigmasterol, lupeol, stearic acid, deoxyelephantopin, and isomers of deoxyelephantopin as described below:

\subsubsection{Stigmasterol}

The stigmasterol was identified in all parts of Elephantopus scaber L. (leaves, roots and stems) in GCMS analysis. Figure 1 shows that the comparison of abundance of stigmasterol in different parts of the plant extracted by the two solvents. All of the samples show that the peaks were in the range of $35.80 \mathrm{~min}$ to $36.10 \mathrm{~min}$ for stigmasterol. Stems of Elephantopus scaber L. contain high level of stigmasterol compound compared to the other parts of the plants. Furthermore, $n$-hexane was more favourable than methanol as extracting solvent during Soxhlet extraction. This can be explained from the peaks of stigmasterol in each parts of the plant in the Figure 1 with different extraction solvents. Besides that, result from gas chromatography (Table 7) also show that the highest percentage area is $8.145 \%$ of stigmasterol compound at 6 hours extraction time with n-hexane as extraction solvent. On the other hand, the leaves sample contain the least stigmasterol compounds. Although the leaves showing the best extraction time of stigmasterol was at 6 hours with n-hexane is same as the conditions applied to stems but it only managed to fulfill $4.850 \%$ area (Table 7). As a result, the best extraction conditions for stigmasterol compound in Elephantopus scaber L. were 6 hours extraction period with n-hexane as solvent and the most favourable parts of the plant for Soxhlet extraction process was stems.

\subsubsection{Lupeol}

Besides stigmasterol, lupeol was also one of the chemical compounds that can be determined from Elephantopus scaber $L$ in the GCMS analysis which was next to the peak of stigmasterol. Peaks of lupeol that were determined from the Figure 2 varied from the time range of $36.80 \mathrm{~min} \sim 37.10 \mathrm{~min}$. All parts of Elephantopus scaber L. plant such as leaves, roots and stems show the presence of lupeol. In addition, $n$-hexane has been identified as the better extraction solvent than methanol. This was because almost all the parts of plant which were extracted with $n$-hexane solvent proposed the higher percentage area in the result of gas chromatography as shown in Table 7. Further the exception were found for 6 hours $(13.556 \%$ area) and 9 hours $(68.550 \%$ area) extraction of stems with $n$-hexane which was lower than the percentage area of methanol at the same extraction time such as $38.590 \%$ (6 hours) and 69.502 (9 hours). For 6 hours 
extraction with $\mathrm{n}$-hexane and methanol in stems, percentages areas for lupeol of both conditions were the lowest. Hence, the result from Table 7 also indicated that the condition of 6 hours extraction time with n-hexane solvent was the most favourable condition for extraction of lupeol compound from leaves $(54.423 \%$ area) while 9 hours with the same solvent for roots $(68.360 \%$ area $)$ and stems $(68.550 \%$ area $)$.

\subsubsection{Stearic acid}

Stearic acid showed its abundance in roots of Elephantopus scaber $L$. which was extracted using hexane as shown in the Figure 3. Next, the time range for the extraction of stearic acid from Elephantopus scaber L. plant was from 21 min to 23 min which also can be identified from the Figure 3.

\subsubsection{Deoxyelephantopin}

Deoxyelephantopin isomers and analogs were identified based on the molecular structure, molecular mass and calculated fragmentation given by Than, N. N. et al. (Than, N.N.. p. 200-204). Deoxyelephantopin isomers and analog 2 were detected in all parts of Elephantopus scaber L. plant by GCMS. In addition, they were showing their abundance peaks from $30 \mathrm{~min}$ to $35 \mathrm{~min}$ resulted from Figure 4. Both leaves samples extracted using n-hexane and methanol showed higher peaks compared to other parts of the plant with same extraction condition. However, deoxyelephantopin analogue 1 was only available in roots sample which was reported in the Figure 5. The time range for the appearance of peaks was $27 \mathrm{~min} \sim 28 \mathrm{~min}$.

\subsection{Statistical Analysis}

Factorial design was used to study the effect of three factors, namely; extraction time, type of solvent, and parts of plant on the percentage extraction of constituents Elephantopus scaber L. The results of factorial design with 72 runs are given in Table 8. The results of analysis of variance (ANOVA) for percentage of extraction obtained from this experiment based on the effect of extraction time, type of solvent and part of plant are given in Table 9. The main effects for all the three parameters were statistically significant $(\mathrm{P}<0.0001)$. In addition to the main effect, all interactions between different factors were also statistically significant $(\mathrm{P}<0.0001)$. Significant interaction (Table 9) indicates that the factors studied did not work independently, rather depend on each other and affect simultaneously on the extent of extraction.

Plot of the main effect using data means for extraction time, type of solvent and parts of plant, is given in Fig.6, which depicts the behavior of each factor individually regardless of other factors. The interaction plot using data means for percentage of extraction is given in Fig.7 that shows the behavior of each factor in presence of other factors, for instance the behavior of extraction time in the presence of type of solvents and parts of plant, the behavior of type of solvents in presence of extraction time and parts of plant, and the behavior of parts of plant in the presence of extraction time and parts of plant on percentage of extraction. The changes in percentage of extraction values were mainly due to the interaction between factors.

The value of $R^{2}$ is high and close to 1 . The value of $R^{2}$ for percentage of extraction was 0.99 which indicates that 0.99 of the total variation is explained by the model that belongs to the extraction time, type of solvent and part of plant and their significant interactions, and only 0.01 of the total variation is unexplained.

\section{Conclusions}

This study has successfully drawn up several conclusions which contributed to Soxhlet extraction process as an alternative method for extraction and separation of chemical constituents from medicinal herbs, Elephantopus scaber $L$. The conclusions of overall study as follows:

(a) The determination of the percentage of extraction for Elephantopus scaber L. were studied at various parts of the plants such as leaves, roots and stems with two types of different solvents, $n$-hexane and methanol, respectively over various extraction period; 3 hours, 6 hours, 9 hours and 12 hours. The study shows that methanol is better than $n$-hexane as solvent regarding extracted yield. Moreover, different parts of the plant have different favourable extraction conditions such as leaves: 12 hours with methanol as solvent and 6 hours with n-hexane as solvent, roots: 9 hours with methanol as solvent and 6 hours with n-hexane as solvent, and stems: 9 hours with methanol as solvent and 9 hours with n-hexane as solvent.

(b) The moisture content and particle size are also the important criteria to conduct the extraction process and their importance can be identified from literature review and experimental process in this study. The tolerable limit of moisture content for Elephantopus scaber L. was around 12\% to $13 \%$.

(c) The study also shows that the extracted crude of Elephantopus scaber L. contains of multi-compounds such as stigmasterol, lupeol, stearic acid, deoxyelephantopin and its isomers/analogs. All of these chemical constituents have different quantity in the plant of Elephantopus scaber L. Maximum extraction condition of stigmasterol was reported as 6 hours extraction with n-hexane as extraction solvent in the stem and reaching $8.145 \%$ area in the gas chromatography 
result. Besides that, extraction condition of lupeol was favourable at 9 hours extraction time with $\mathrm{n}$-hexane in the stems as reported $68.580 \%$ area in the gas chromatogram.

\section{References}

Galhiane, M.S., Rissato, S.R., Chierice, G.O., Almeida, M.V., \& Silva, L.C. (2006). Influence of different extraction methods on the yield and linalool content of the extracts of Eugenia uniflora L. Talanta. 70, 286-292.

Klejdus, B., Mikelova, R., Adam,V., Zehnalek, J., Vacek, J., \& Kizek, R. (2004). Liquid chromatographic-mass spectrophotometric determination of genistin and daidzin in soybean food samples after accelerated solvent extraction with modified content of extraction cell. Analytica Chimica Acta, 517, 1-11.

Klejdus, B., Mikelova, R., Petrolova, J., Potesil, D., Adam, V., \& Stiborova, M., (2005). Evaluation of isoflavone aglycon and glycoside distribution in soy plants and soybeans by fast column high-performance liquid chromatography coupled with a diode-array detector. Journal of Agricultural and Food Chemistry. 53, 5848-5852.

Luque de Castro, M. D., Valcarcel, M. \& Tena, M. T. (1994), Analytical Supercritical Fluid Extraction, Butterworth Publishers, Boston.

Luque de Castro, M.D. \& Garcia-Ayuso, L.E. (1998). Soxhlet extraction of solid materials: An outdated technique with a promising innovative future. Analytica Chimica Acta. 369, 1-10.

Mamidipally, P.K., \& Liu,S.X.(2004). First approach on rice bran oil extraction using limonene. European Journal of Lipid Science and Technology. 106, 122-125.

Peer, L. M. \& Metzger, J. (1980), Medicinal Plants of East and Southeast Asia: Attributed Properties and Uses. The MIT Press. London.

Reverchon, E. (1997). Supercritical Fluid Extraction and fractionation of Essential Oils and Related Products. $J$. of Supercritical Fluids. 10, 1-37.

Romdhane, M. \& Gourdou, C. (2002). Investigation in solid-liquid extraction influence of ultrasound. Chem. Eng. J. 87, 11-19.

Than, N.N., Fotso, S., Sevvana, M., Sheldrick, G. M., Fiebigd, H. H., Kelter, G., \& Laatsch, H. (2005). Sesquiterpene lactones from Elephantopus scaber. Z. Naturforsch. 60b, 200-204.

Tsai, C. C \& Lin, C. C. (1999). Anti-inflammatory effects of Taiwan folk medicine "Teng-Khia-U” on carrageenan and adjuvant-induced paw edema in rats. J. Ethnopharm. 64, 85-89.

Wheelwring, E.G. (1974), Medicinal Plants and their History. Dover Publications, New York.

Zarnowski, R., \& Suzuki, Y.(2004). Expedient Soxhlet extraction of resorcinolic lipids from wheat grains. Journal of Food Composition and Analysis, 17, 649-664.

Zlotorzynski, A. (1995). Methanol has relatively higher dissipation factor, which means that it could absorb much of the microwave energy and transform it into heat better than other solvents. Crit. Rev. Anal. Chem. 25, 43-75.

Table 1. Sample Preparation Result

\begin{tabular}{|c|c|c|c|}
\hline Description & Leave & Root & Stem \\
\hline Fresh sample & 537.94 & 220.78 & 219.53 \\
\hline After chop & 524.14 & 212.86 & 212.45 \\
\hline After grind & 492.58 & 198.47 & 196.95 \\
\hline
\end{tabular}


Table 2. Particle Size Percentages

\begin{tabular}{|c|c|c|c|c|c|}
\hline Parts & Smaller than 150 $\boldsymbol{\mu m}$ & $\mathbf{1 5 0} \boldsymbol{\mu m}$ & $\mathbf{1 8 0} \boldsymbol{\mu m}$ & $\mathbf{2 5 0} \boldsymbol{\mu m}$ & $\mathbf{3 0 0} \boldsymbol{\mu m}$ \\
\hline Leaves & $50.56 \%$ & $14.22 \%$ & $18.32 \%$ & $13.63 \%$ & $3.27 \%$ \\
\hline Steam & $0.98 \%$ & $2.20 \%$ & $95.75 \%$ & $0.67 \%$ & $0.40 \%$ \\
\hline Root & $93.91 \%$ & $1.68 \%$ & $2.75 \%$ & $1.20 \%$ & $0.46 \%$ \\
\hline
\end{tabular}

Table 3. Moisture Content Determinations

\begin{tabular}{|c|c|c|c|c|c|c|c|c|c|}
\hline \multirow{2}{*}{ Description } & \multicolumn{3}{|c|}{ Leave } & \multicolumn{3}{|c|}{ Root } & \multicolumn{3}{|c|}{ Stem } \\
\hline & 1 & 2 & 3 & 1 & 2 & 3 & 1 & 2 & 3 \\
\hline $\begin{array}{c}\text { Empty dish }\left(m_{\theta}\right) \\
(\mathrm{gm})\end{array}$ & 39.1941 & 37.6534 & 40.6425 & 36.1688 & 38.2890 & 35.8629 & 37.0875 & 36.5648 & 38.7524 \\
\hline $\begin{array}{c}\text { Dish + sample } \\
\text { (initial) }\left(m_{l}\right) \\
\text { (gm) }\end{array}$ & 44.1932 & 42.6545 & 45.6433 & 41.1681 & 43.2893 & 40.8627 & 42.0871 & 41.5653 & 43.7532 \\
\hline $\begin{array}{c}\text { Dish + sample } \\
\text { (final) }\left(m_{2}\right) \\
(\mathrm{gm})\end{array}$ & 43.7460 & 42.2076 & 45.1974 & 40.7315 & 42.8535 & 40.4265 & 41.6573 & 41.1360 & 43.3224 \\
\hline $\begin{array}{c}\text { Moisture content } \\
\text { percentage }\end{array}$ & 8.95 & 8.94 & 8.92 & 8.73 & 8.72 & 8.72 & 8.60 & 8.59 & 8.61 \\
\hline $\begin{array}{c}\text { Average } \\
\text { percentage }\end{array}$ & \multicolumn{3}{|c|}{8.94} & \multicolumn{3}{|c|}{8.72} & \multicolumn{3}{|c|}{8.60} \\
\hline
\end{tabular}

Table 4. Percentage of Extraction of oil from Leaves using n- hexane and Methanol

\begin{tabular}{|c|c|c|c|c|c|c|c|c|}
\hline \multirow{4}{*}{$\begin{array}{c}\text { Extraction } \\
\text { Time } \\
\text { (Hours) }\end{array}$} & \multicolumn{8}{|c|}{ Percentage of Extraction (\%) } \\
\hline & \multicolumn{4}{|c|}{ n- hexane } & \multicolumn{4}{|c|}{ Methanol } \\
\hline & \multicolumn{3}{|c|}{ Replications } & \multirow{2}{*}{ Average } & \multicolumn{3}{|c|}{ Replications } & \multirow{2}{*}{ Average } \\
\hline & I & II & III & & $\mathbf{I}$ & II & III & \\
\hline 3 & 6.61 & 7.39 & 6.92 & 6.97 & 11.78 & 12.49 & 12.53 & 12.27 \\
\hline 6 & 7.69 & 7.32 & 8.36 & 7.79 & 11.23 & 10.75 & 10.95 & 10.98 \\
\hline 9 & 6.49 & 7.35 & 6.18 & 6.67 & 12.91 & 13.26 & 12.53 & 12.90 \\
\hline 12 & 7.25 & 7.48 & 7.61 & 7.45 & 13.69 & 14.36 & 14.18 & 14.08 \\
\hline
\end{tabular}


Table 5. Percentage of Extraction of oil from Roots using n- hexane and Methanol

\begin{tabular}{|c|c|c|c|c|c|c|c|c|}
\hline \multirow{4}{*}{$\begin{array}{c}\text { Extraction } \\
\text { Time } \\
\text { (Hours) }\end{array}$} & \multicolumn{8}{|c|}{ Percentage of Extraction (\%) } \\
\hline & \multicolumn{4}{|c|}{ n- hexane } & \multicolumn{4}{|c|}{ Methanol } \\
\hline & \multicolumn{3}{|c|}{ Replications } & \multirow{2}{*}{ Average } & \multicolumn{3}{|c|}{ Replications } & \multirow{2}{*}{ Average } \\
\hline & I & II & III & & I & II & III & \\
\hline 3 & 5.25 & 4.85 & 4.97 & 5.02 & 7.33 & 6.84 & 7.14 & 7.10 \\
\hline 6 & 6.11 & 6.48 & 5.63 & 6.07 & 8.59 & 9.38 & 8.92 & 8.96 \\
\hline 9 & 5.12 & 4.76 & 4.43 & 4.77 & 9.73 & 10.27 & 10.52 & 10.17 \\
\hline 12 & 5.20 & 5.58 & 5.72 & 5.50 & 9.61 & 10.20 & 9.92 & 9.91 \\
\hline
\end{tabular}

Table 6. Percentage of Extraction of oil from stems using n- hexane and Methanol

\begin{tabular}{|c|c|c|c|c|c|c|c|c|}
\hline \multirow{4}{*}{$\begin{array}{c}\text { Extraction } \\
\text { Time } \\
\text { (Hours) }\end{array}$} & \multicolumn{8}{|c|}{ Percentage of Extraction (\%) } \\
\hline & \multicolumn{4}{|c|}{ n- hexane } & \multicolumn{4}{|c|}{ Methanol } \\
\hline & \multicolumn{3}{|c|}{ Replications } & \multirow{2}{*}{ Average } & \multicolumn{3}{|c|}{ Replications } & \multirow{2}{*}{ Average } \\
\hline & I & II & III & & I & II & III & \\
\hline 3 & 3.28 & 2.87 & 3.56 & 3.24 & 4.47 & 5.39 & 4.17 & 4.68 \\
\hline 6 & 5.00 & 5.38 & 4.72 & 5.03 & 5.11 & 5.52 & 4.76 & 5.13 \\
\hline 9 & 5.37 & 5.48 & 4.92 & 5.26 & 10.16 & 10.63 & 9.74 & 10.18 \\
\hline 12 & 4.36 & 4.76 & 5.18 & 4.77 & 10.10 & 9.69 & 10.63 & 10.14 \\
\hline
\end{tabular}

Table 7. Summary of compounds detected in plant from GC

\begin{tabular}{|c|c|c|c|c|c|c|c|}
\hline \multirow{3}{*}{ Parts } & \multirow{3}{*}{ Compounds } & \multicolumn{6}{|c|}{ Percentage Area } \\
\hline & & \multicolumn{3}{|c|}{ n-hexane } & \multicolumn{3}{|c|}{ methanol } \\
\hline & & 6 hours & 9 hours & 12 hours & 6 hours & 9 hours & 12 hours \\
\hline \multirow{2}{*}{ Roots } & Stigmasterol & 5.369 & - & 4.766 & - & - & - \\
\hline & Lupeol & 58.890 & 68.360 & 53.695 & 47.445 & 55.405 & 41.790 \\
\hline \multirow{2}{*}{ Stems } & Stigmasterol & 8.145 & - & 4.447 & 3.468 & - & 4.451 \\
\hline & Lupeol & 13.556 & 68.550 & 58.681 & 38.590 & 69.502 & 54.077 \\
\hline \multirow{2}{*}{ Leaves } & Stigmasterol & 4.850 & 3.356 & 3.939 & 3.955 & 4.372 & 3.666 \\
\hline & Lupeol & 54.423 & 53.017 & 51.713 & 53.213 & 45.272 & 49.862 \\
\hline
\end{tabular}


Table 8. Factorial design with experimental data values for extraction $\%$

\begin{tabular}{|c|c|c|c|c|c|c|c|}
\hline Time & Solvent & plant & Part of plant & Time & solvent & plant & Part of plant \\
\hline 3 & n-Hexane & Leaves & 6.61 & 9 & n-Hexane & Leaves & 6.49 \\
\hline 3 & n-Hexane & Leaves & 7.39 & 9 & n-Hexane & Leaves & 7.35 \\
\hline 3 & n-Hexane & Leaves & 6.92 & 9 & n-Hexane & Leaves & 6.18 \\
\hline 3 & n-Hexane & Roots & 5.25 & 9 & n-Hexane & Roots & 5.12 \\
\hline 3 & n-Hexane & Roots & 4.85 & 9 & n-Hexane & Roots & 4.76 \\
\hline 3 & n-Hexane & Roots & 4.97 & 9 & n-Hexane & Roots & 4.43 \\
\hline 3 & n-Hexane & Stems & 3.28 & 9 & n-Hexane & Stems & 5.37 \\
\hline 3 & n-Hexane & Stems & 2.87 & 9 & n-Hexane & Stems & 5.48 \\
\hline 3 & n-Hexane & Stems & 3.56 & 9 & n-Hexane & Stems & 4.92 \\
\hline 3 & Methanol & Leaves & 11.78 & 9 & Methanol & Leaves & 12.91 \\
\hline 3 & Methanol & Leaves & 12.49 & 9 & Methanol & Leaves & 13.26 \\
\hline 3 & Methanol & Leaves & 12.53 & 9 & Methanol & Leaves & 12.53 \\
\hline 3 & Methanol & Roots & 7.33 & 9 & Methanol & Roots & 9.73 \\
\hline 3 & Methanol & Roots & 6.84 & 9 & Methanol & Roots & 10.27 \\
\hline 3 & Methanol & Roots & 7.14 & 9 & Methanol & Roots & 10.52 \\
\hline 3 & Methanol & Stems & 4.47 & 9 & Methanol & Stems & 10.16 \\
\hline 3 & Methanol & Stems & 5.39 & 9 & Methanol & Stems & 10.63 \\
\hline 3 & Methanol & Stems & 4.17 & 9 & Methanol & Stems & 9.74 \\
\hline 6 & n-Hexane & Leaves & 7.69 & 12 & n-Hexane & Leaves & 7.25 \\
\hline 6 & n-Hexane & Leaves & 7.32 & 12 & n-Hexane & Leaves & 7.48 \\
\hline 6 & n-Hexane & Leaves & 8.36 & 12 & n-Hexane & Leaves & 7.61 \\
\hline 6 & n-Hexane & Roots & 6.11 & 12 & n-Hexane & Roots & 5.2 \\
\hline 6 & n-Hexane & Roots & 6.48 & 12 & n-Hexane & Roots & 5.58 \\
\hline 6 & n-Hexane & Roots & 5.63 & 12 & n-Hexane & Roots & 5.72 \\
\hline 6 & n-Hexane & Stems & 5 & 12 & n-Hexane & Stems & 4.36 \\
\hline 6 & n-Hexane & Stems & 5.38 & 12 & n-Hexane & Stems & 4.76 \\
\hline 6 & n-Hexane & Stems & 4.72 & 12 & n-Hexane & Stems & 5.18 \\
\hline 6 & Methanol & Leaves & 11.23 & 12 & Methanol & Leaves & 13.69 \\
\hline 6 & Methanol & Leaves & 10.75 & 12 & Methanol & Leaves & 14.36 \\
\hline 6 & Methanol & Leaves & 10.95 & 12 & Methanol & Leaves & 14.18 \\
\hline 6 & Methanol & Roots & 8.59 & 12 & Methanol & Roots & 9.61 \\
\hline 6 & Methanol & Roots & 9.38 & 12 & Methanol & Roots & 10.2 \\
\hline 6 & Methanol & Roots & 8.92 & 12 & Methanol & Roots & 9.92 \\
\hline 6 & Methanol & Stems & 5.11 & 12 & Methanol & Stems & 10.1 \\
\hline 6 & Methanol & Stems & 5.52 & 12 & Methanol & Stems & 9.69 \\
\hline 6 & Methanol & Stems & 4.76 & 12 & Methanol & Stems & 10.63 \\
\hline
\end{tabular}


Table 9. The results of analysis of variance (ANOVA) for percentage of extraction \%

\begin{tabular}{|c|c|c|c|c|c|}
\hline Source & D.F & Sum of Squares & Mean Square & F-Value & P-value \\
\hline Extraction Time & 3 & 49.37 & 16.46 & 107.85 & $<0.0001$ \\
\hline Type of solvent & 1 & 287.40 & 287.40 & 1883.63 & $<0.0001$ \\
\hline Parts of plant & 2 & 186.31 & 93.15 & 610.54 & $<0.0001$ \\
\hline Time*solvent & 3 & 42.14 & 14.05 & 92.07 & $<0.0001$ \\
\hline Time* plant & 6 & 27.97 & 4.66 & 30.55 & $<0.0001$ \\
\hline Solvent * plant & 2 & 17.76 & 8.88 & 58.19 & $<0.0001$ \\
\hline Time*Solvent*Plant & 6 & 8.78 & 1.46 & 9.59 & $<0.0001$ \\
\hline Error & 48 & 7.32 & 0.15 & & \\
\hline Total & 71 & 627.04 & & & \\
\hline
\end{tabular}

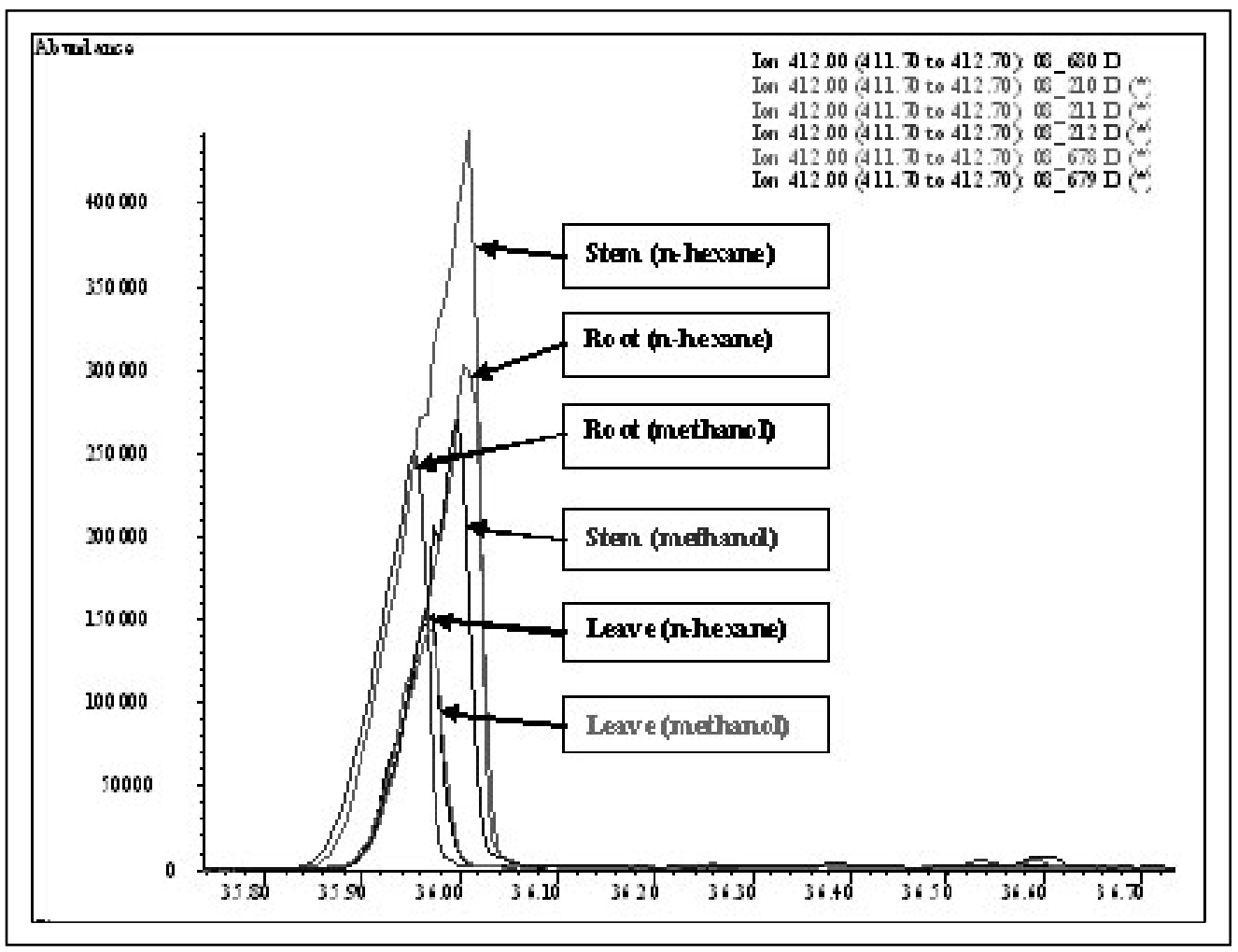

Figure 1. Chromatogram and mass spectrum of Stigmasterol 


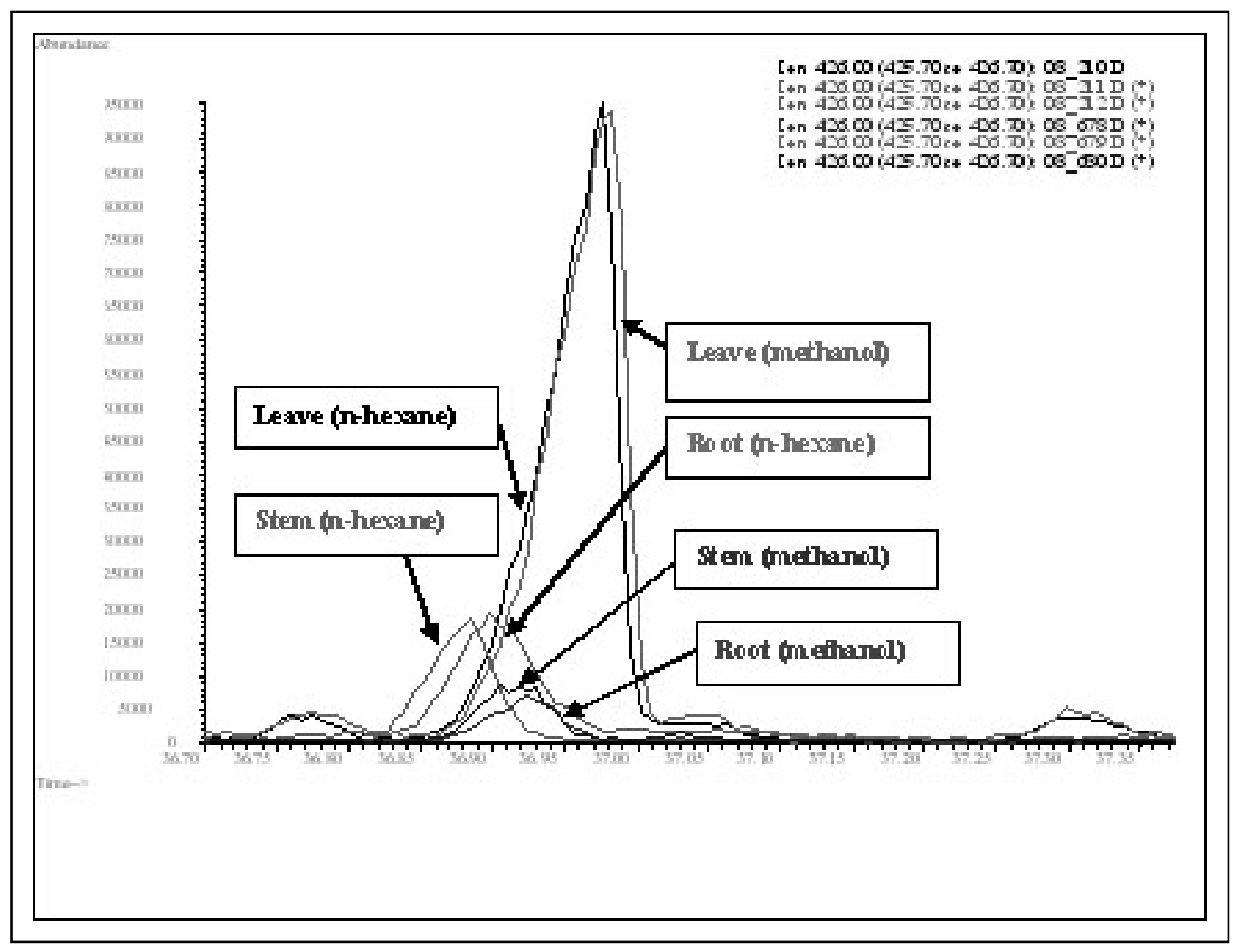

Figure 2. Chromatogram and mass spectrum of lupeol

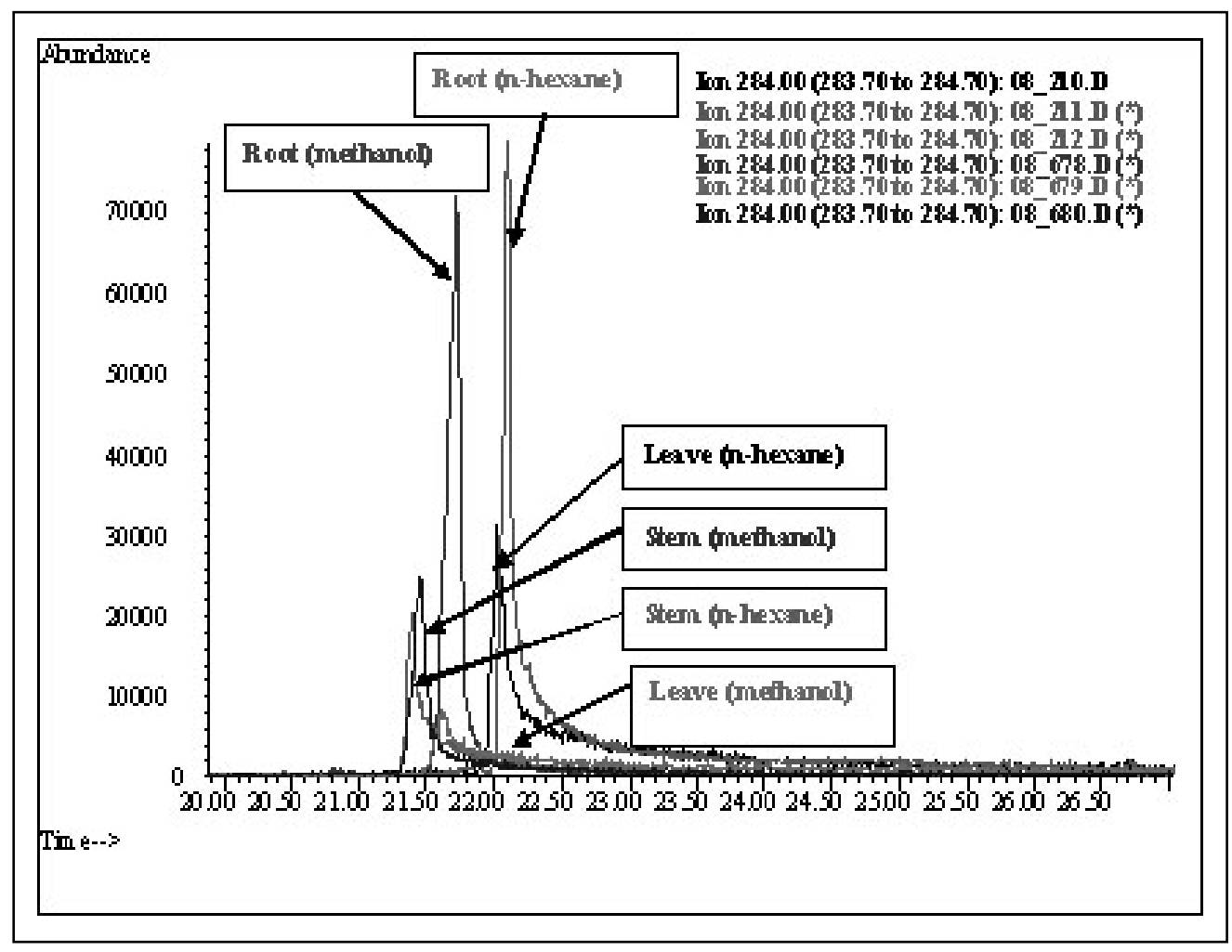

Figure 3. Chromatogram and mass spectrum of stearic acid 


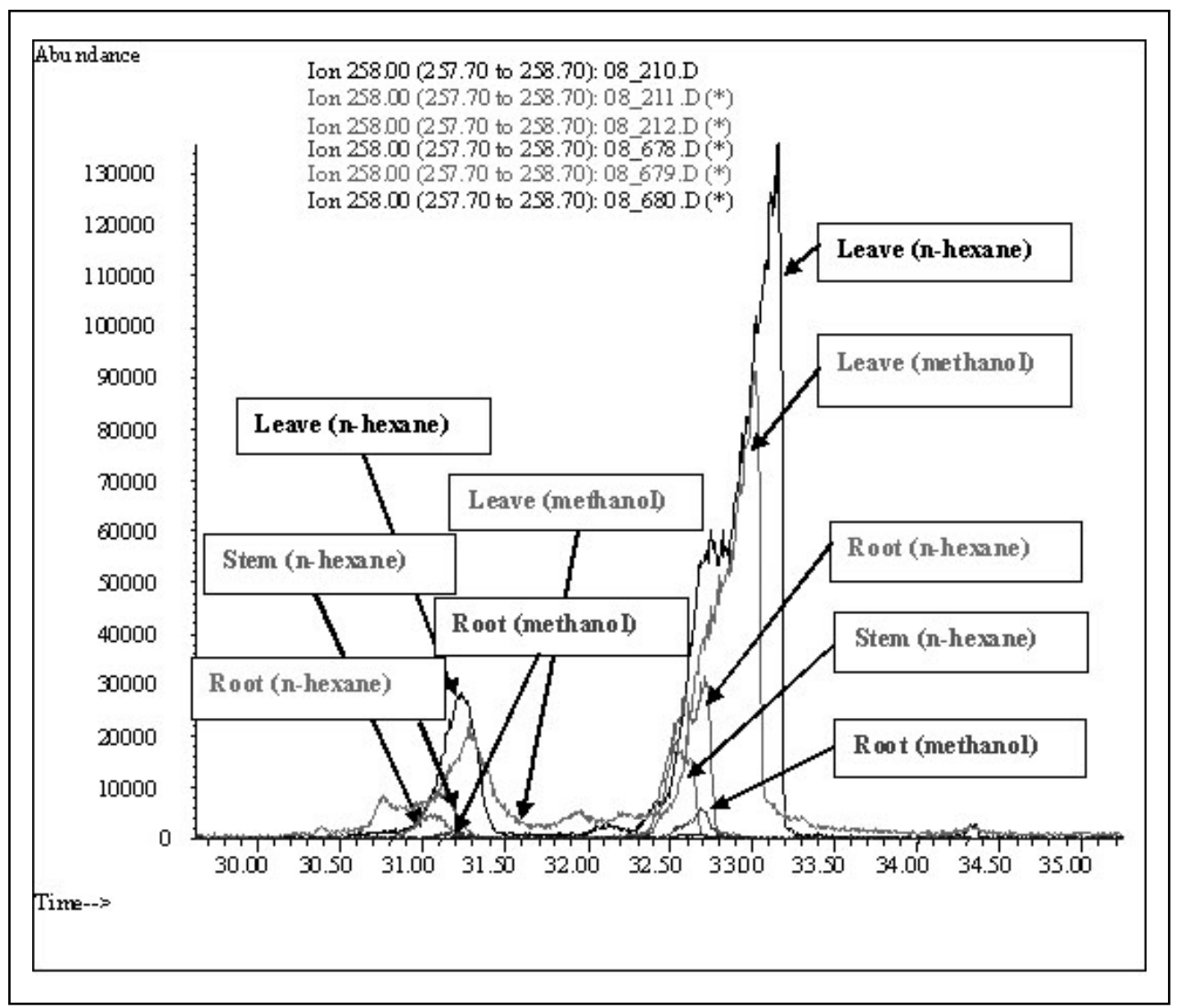

Figure 4. Chromatogram and mass spectrum of deoxyelephantopin isomers and analogue 2

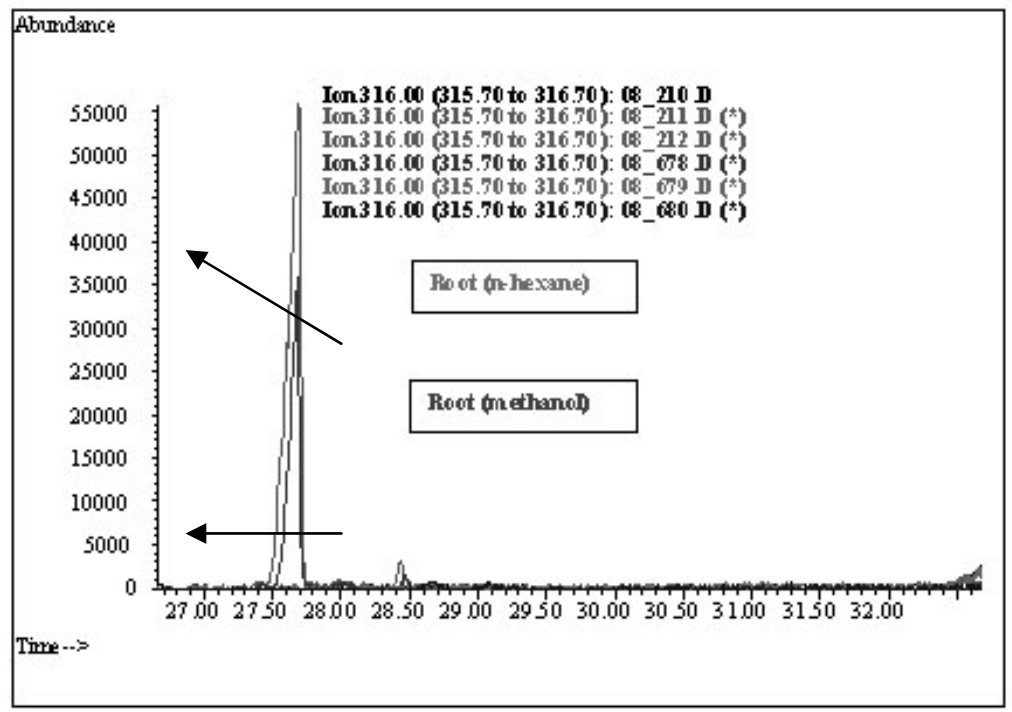

Figure 5. Chromatogram and mass spectrum of deoxyelephantopin analogue 1 


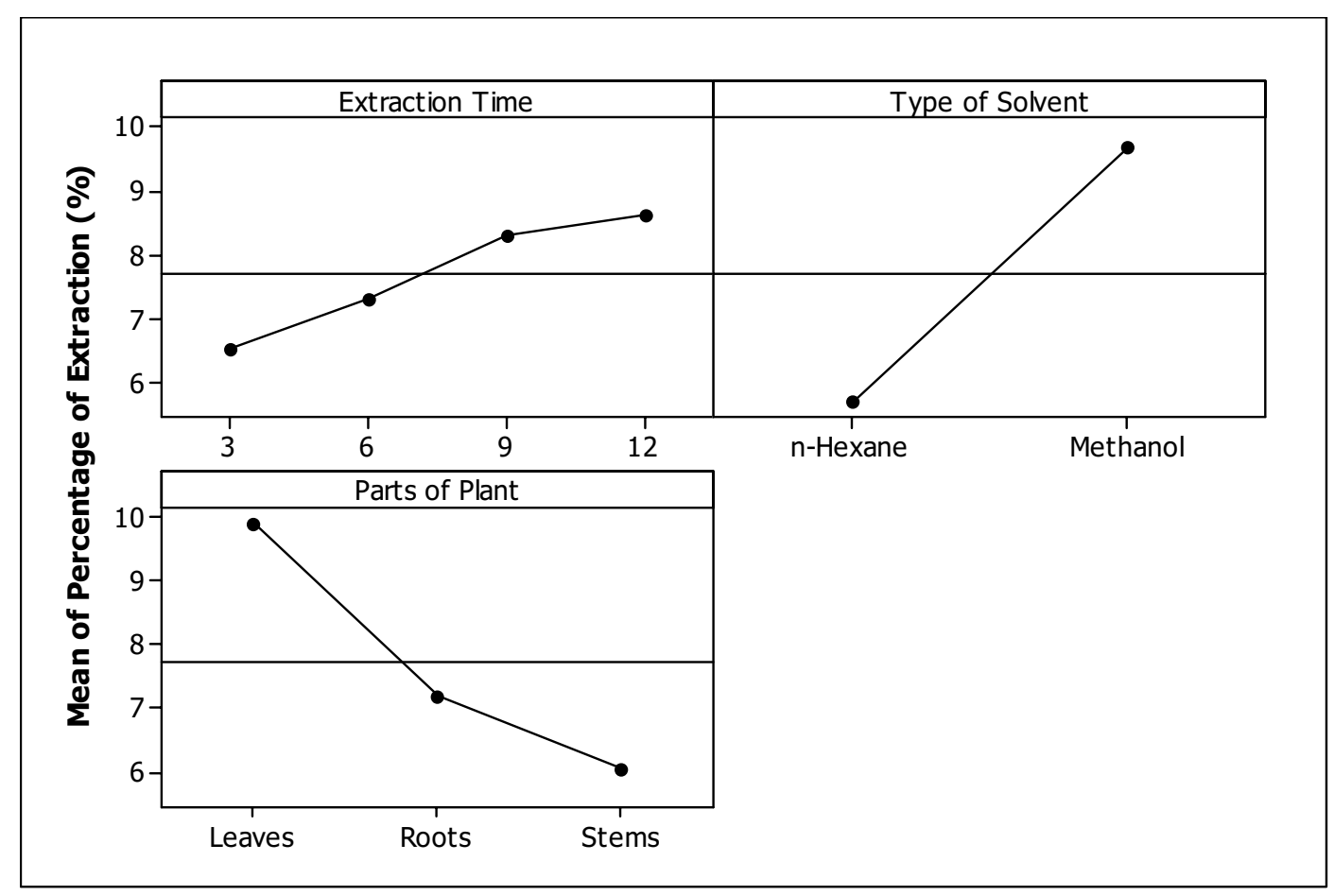

Figure 6. Mean effect plot (data means) of \% extraction vs extraction time, type of solvent and part of plant

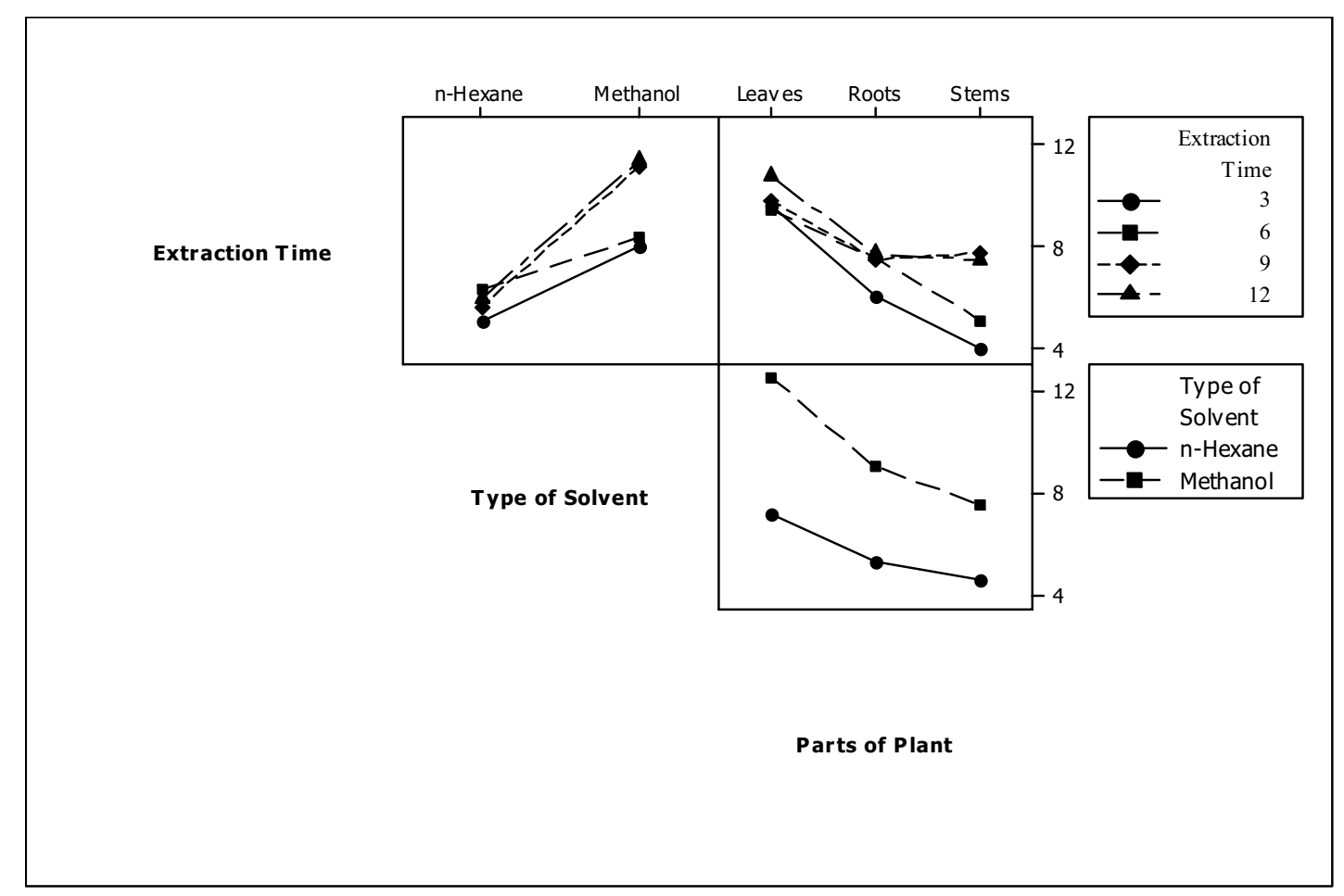

Figure 7. Interaction plot (data means) of Percentage extraction 